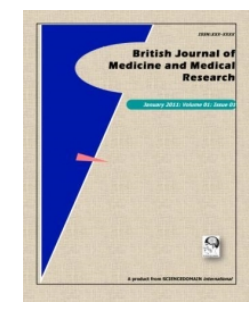

British Journal of Medicine \& Medical Research

3(3): 543-554, 2013

SCIENCEDOMAIN international

www.sciencedomain.org

\title{
The Effect of Cytokines on MicroRNA Expression in TW01 Nasopharyngeal Carcinoma Cells
}

\author{
Ting Wei Lee ${ }^{1}$, Eng Lai $\mathrm{Tan}^{2}$, Ching Ching $\mathrm{Ng}^{3}$ and Sook Yee $\mathrm{Gan}^{2^{*}}$ \\ ${ }^{1}$ Institute of Postgraduate Studies and Research, International Medical University, No. 126 \\ Jalan 19/155B, Bukit Jalil, 57000 Kuala Lumpur, Malaysia. \\ ${ }^{2}$ School of Pharmacy, International Medical University, No. 126 Jalan 19/155B, Bukit Jalil, \\ 57000 Kuala Lumpur, Malaysia. \\ ${ }^{3}$ Institute of Biological Sciences, Faculty of Science, University of Malaya, 50603 Kuala \\ Lumpur, Malaysia.
}

Authors' contributions

This work was carried out in collaboration between all authors. Author SYG designed and coordinated the study; and facilitated in the drafting and reviewing of the manuscript. Author SYG also contributed in the application for grant. Author TWL conducted all the experiments and statistical analysis, and participated in the drafting of the manuscript. Authors ELT and CCN supervised the research work and helped in reviewing the manuscript. All authors have reviewed and approved the final manuscript.

Research Article

Received $30^{\text {th }}$ October 2012

Accepted $28^{\text {th }}$ December 2012

Published $27^{\text {th }}$ February 2013

\section{ABSTRACT}

Aims: To determine the effect of cytokines, namely transforming growth factor-beta one (TGF- 31 ), and interleukin-6 (IL-6) on the expression of 88 cancer-related microRNAs (miRNAs) in TW01 nasopharyngeal carcinoma (NPC) cells with or without the presence of Epstein-Barr virus latent membrane protein 1 (LMP1).

Methodology: TW01 and TW01-LMP1 cells were treated with cytokines. MicroRNAs were isolated from treated and untreated TW01/TW01-LMP1 cells and were subjected to RT-PCR array of 88 cancer-related microRNAs. The threshold cycle $(\mathrm{Ct})$ data were analysed and fold-change in the level of gene expression was calculated based on $\triangle \Delta \mathrm{Ct}$ using two endogenous controls, SNORD 47 and SNORD 44. Data obtained from each treatment were compared with the data obtained from the respective control group (untreated TW01/ TW01-LMP1). 
Results: TGF- $\beta 1$ down-regulated miR-143 in TW01 NPC cells. In TW01 cells that expressed the EBV LMP1 gene (TW01-LMP1), approximately $97 \%$ of the 88 miRNAs were up-regulated by TGF- $\beta 1$. Among them was miR-181c a well-known repressor of NOTCH2/4 and KRAS and has important role in cell differentiation. IL-6 up-regulated approximately $65 \%$ of the miRNAs in TW01 cells but in less than four-fold. In TW0LMP1 cells, eight miRNAs; namely, miR-15b, miR-155, miR-16, miR-215, miR-23b, miR-25, miR-9 and miR-98 were significantly up-regulated by IL-6. Among these, miR$15 \mathrm{~b}, \mathrm{miR}-155$ and miR-25 had been reported to be elevated in NPC tissues.

Conclusion: This study provides a preliminary perspective on the effects of cytokines on the expression of miRNAs in TW01 NPC cells.

Keywords: microRNA; cytokines; nasopharyngeal carcinoma; Epstein-Barr; latent membrane protein one.

\section{INTRODUCTION}

MicroRNAs (miRNAs) are small non-coding protein RNAs, which are approximately 22 nucleotides in length. They can either bind to their target mRNAs by complete base pairing which subsequently leads to mRNA cleavage, or they can bind to their targets' 3'UTR partially to cause translational repression [1]. MicroRNAs are believed to play significant roles in cancer development because most reported human miRNAs are located within the cancer-associated regions [2]. Down-regulation of twenty four miRNAs (including miR-143, miR-145, miR-187, miR-195, miR-204, miR-34c-3p and miR449a) in nasopharyngeal carcinoma (NPC) tissues was associated with several oncogenic pathways such as VEGF signalling, Inositol 1, 4, 5-triphosphate (IP3) signalling and TGF-Wnt pathways [3]. Upregulation of miR-141 in NPC reduced the level of its target mRNAs (BRD3, UBAP1 and PTEN) and eventually led to NPC development [4].

In NPC, increased expression of cytokines was correlated with advanced stage and adverse prognosis. Interleukin-6 (IL-6), a pro-inflammatory cytokine which mediates Epstein-Barr virus (EBV) latent infection in NPC [5] was activated by NF-kB activity [6]. Transforming growth factor beta-one (TGF- $\beta 1$ ) is a multifunctional cytokine which plays a dualistic role in carcinogenesis [7]. High level of TGF- $\beta 1$ disrupted the EBV latency and induced its replication [8]. In addition, TGF- $\beta 1$ induced production of EBV-specific IgA which is involved in the pathogenesis of NPC [9].

EBV infection has been associated with the progression of NPC although it is predominantly latent [10]. EBV associated NPC cells suppressed immunogenic response by releasing exosomes containing LMP1 which inhibited the activity of T-cells [11]. LMP1 also induced the expression of Snail which may play a role in epithelial-mesenchymal transition (EMT) of NPC leading to metastasis [12]. In addition, angiogenesis is induced by LMP1 via the expression of cyclooxygenase-2 (COX-2) which is associated with the production of vascular endothelial growth factor (VEGF) [13]. Although LMP1 may play a prime role in driving the development of NPC, it was expressed variably in NPC tissues [14].

MicroRNAs were reported to be associated with cytokines leading to the progression of cancer. Overexpression of miR-106b-25 and miR-17-92 clusters inactivated the TGF- $\beta$ signalling in several tumours leading to resistance to TGF- $\beta$ tumour suppression [15]. TGF$\beta 1$ induced expression of miR-21 which targets tumour suppressor genes [16]. It activated Akt kinase by targeting phosphatase and tensin homologue (PTEN) via the induction of miR- 
$216 a$ and miR-217 [17]. Reduced miR-23b may activate the TGF- $\beta 1 / S m a d 3$ signalling pathway during termination stage of liver regeneration [18]. In addition, TGF $\beta / S m a d$ pathway could regulate miRNA-155 and resulted in epithelial cell plasticity by targeting RhoA [19]. In rheumatoid arthritis, miR-155 could be involved in posttranscriptional control of the inflammatory pathways by increasing production of IL-6 [10]. It was also reported that latent membrane protein 1 (LMP1) activated NF-KB pathway resulted in induced expression of miR-155 which may be involved in EBV-mediated transformation of $B$ cells [21]. The objectives of this study are to determine the expression of 88 cancer related miRNAs in TW01/TW01-LMP1 cells in the presence of TGF- $\beta 1$ and IL-6.

\section{MATERIALS AND METHODS}

NPC cell line, TW01 was an established cell line derived from an EBV-negative, moderately differentiated keratinising NPC tissues. TW01 cells were cultured with DMEM/F12 (Invitrogen, USA) supplemented with $10 \% \mathrm{v} / \mathrm{v}$ fetal bovine serum (FBS). TW01 cells that transiently expressed the EBV LMP1 gene (TW01-LMP1 cells) were established via transfection of TW01 with LMP1 gene using the LipofectamineTM 2000 (Invitrogen, USA) as described by Chew et al. [22]. Transient expression of LMP1 gene was confirmed by conducting RT-PCR analysis via SuperscriptTM III One-Step RT-PCR System (Invitrogen, USA). Total RNA was extracted using RNeasy Mini Kit (Qiagen, Germany) and RT-PCR analysis was performed using LMP1 gene specific primers: 5'CACCATGATGGAACACGACCTTGAG-3' and 5'-GACAGTGTGGCTAAGGGA-3'. Untransfected TW01 cells were used as control. Protein expression was further verified by performing western blot analysis with monoclonal mouse anti-EBV LMP1 CS. 1-4 (Dako, Denmark). Transient expression of LMP1 in TW01-LMP1 cells was confirmed via RT-PCR and western blot analysis (Fig.1). The transcription of LMP1 gene was indicated by the detection of a fragment of $1373 \mathrm{bp}$ in the RT-PCR product. No bands were detected in the RT-PCR products of untransfected TW01 cells. The genomic control (PCR product of total RNA isolated from transfected TW01 cells) also produced negative results. Presence of LMP1 protein was further confirmed by western blot which detected a band of $57 \mathrm{kDa}$ (Fig. 1).

A total of $1.5 \times 10^{6}$ TW01/ TW01-LMP1 cells were plated into a culture flask 24 hours prior to treatment with cytokines $(1000 \mathrm{pg} / \mathrm{mL}$ TGF- $\beta 1$ or $100 \mathrm{pg} / \mathrm{ml} \mathrm{IL-6)}$ for 48 hours. Untreated cells were also cultured for 48 hours. miRNAs were then isolated using mirVana ${ }^{\mathrm{TM}}$ miRNA Isolation Kit (Ambion, UK). The concentration and quality of miRNAs were determined using the Infinite 200 (TECAN, Switzerland). The integrity of miRNAs was also analysed by BioAnalyzer 2100 (Agilent Technologies, USA) using both Agilent Small RNA kit as well as Agilent RNA 6000 Nano Kit. miRNAs with A260/A280 ratio of $1.9-2.1$, A260/A230 ratio of $1.7-2.1$ and RNA integrity number (RIN) $\geq 9$ were subjected to the RT2 miRNA PCR Array of 88 cancer-related miRNAs (MAH102A, SABiosciences, USA). A total of $100 \mathrm{ng}$ miRNAs were converted into cDNA using the RT2 miRNA first strand kit and the quantitative RT-PCR was performed via the iQ5 real-time PCR system (Bio-Rad Laboratories, USA). The PCR condition was set to $95^{\circ} \mathrm{C}$ for $10 \mathrm{~min}$, followed by 40 cycles of $95^{\circ} \mathrm{C}$ for $15 \mathrm{~s}, 60^{\circ} \mathrm{C}$ for $30 \mathrm{~s}$ and $72^{\circ} \mathrm{C}$ for $30 \mathrm{~s}$. The threshold cycle $(\mathrm{Ct})$ data were analysed using integrated web-based software (SABioscience RT2 Profiler PCR Array Data Analysis version 3.4). Fold-change was calculated based on $\triangle \triangle \mathrm{Ct}$ using two endogenous controls, SNORD 47 and SNORD 44 for normalisation. Data obtained from each treatment were compared with the data obtained from the respective control group (untreated TW01/ untreated TW01-LMP1). 


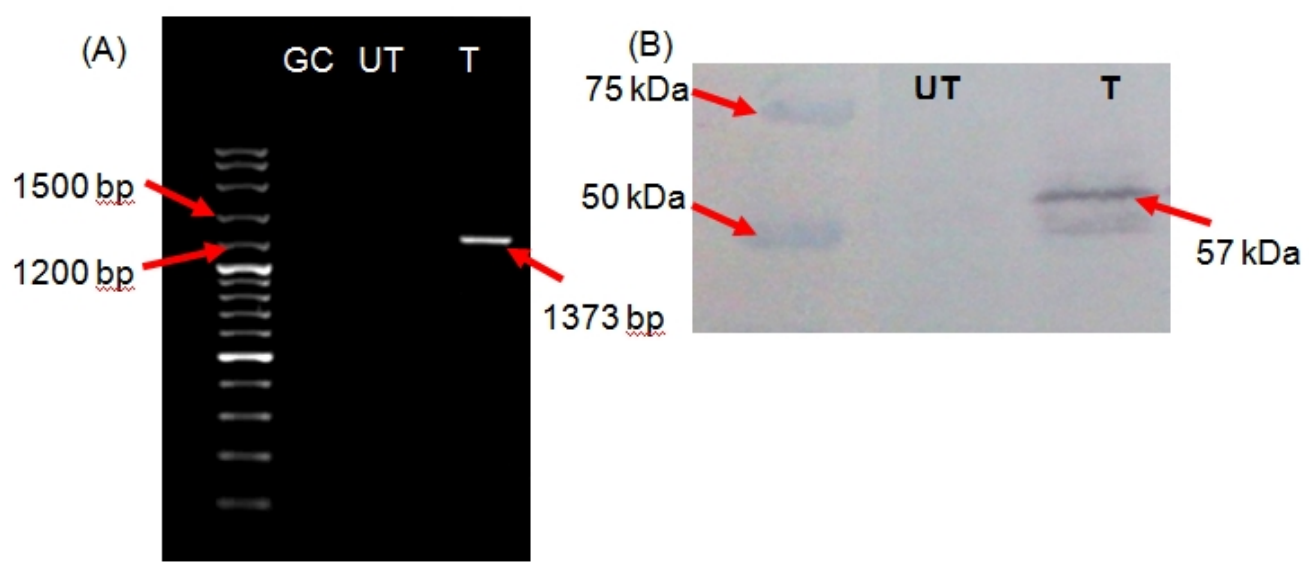

Fig. 1. Transient expression of LMP1 gene in TW01-LMP1 cells was confirmed by RTPCR and Western blot analysis

(A) The transcription of LMP1 in transfected TW01 (T) was indicated by the presence of RT-PCR product of $1373 \mathrm{bp}$. No bands were found with the genomic control (GC) and untransfected TW01 cells (UT). (B) Expression of LMP1 was verified by the presence of $57 \mathrm{kDa}$ protein via Western Blotting.

\section{RESULTS AND DISCUSSION}

Results from the RT-PCR array showed $54 \%$ of the 88 cancer related miRNAs were downregulated by TGF- $\beta 1$ in TW01 when compared with untreated TW01 cells (Fig.2). A group of eight miRNAs was significantly down-regulated. Among them were tumour suppressors such as miR-122 [23], miR-142-5p [24], miR-143 [25] and miR-206 [26]. Down-regulation of these miRNAs was reported to either increase cell proliferation or reduce apoptosis. Three miRNAs (miR-143, miR-142-5p and miR-372) were down-regulated more than ten-fold. However, there was limited information on the roles of these miRNAs in NPC. Downregulation of miR-143 was observed in NPC [3], cervical cancer [27] and B-cell malignancies [28]. The down-regulation of miR-143 has been suggested to activate the mitogen-activated protein kinase (MAPK) pathway via extracellular signal-regulated kinase 5 (ERK5), which is a miR-143 target [29]. It is also possible that miR-143 is associated with TGF- $\beta 1$ in the activation of ERK5/MAPK. Down-regulation of miR-372 has been reported in cervical cancer. miR-372 is known to target cyclin-dependent kinase 2 (CDK2) and Cyclin A1 and its overexpression had been shown to suppress cell growth by inducing cell-cycle arrest [30]. Oncogenic activity of miR-372 was observed in human testicular germ cell tumours where it targeted the p53 pathway [31] and in human gastric cancer cell line where it down-regulated the tumour-suppressor gene LATS2 [32]. However, the effect of miR-372 in NPC has not been documented. In order to predict cellular pathways that are associated with the downregulation of the eight miRNAs, we conducted multiple microRNA analysis using the DIANAmirPath based on TargetScan 5 [33]. Through these analyses, the eight miRNAs were predicted to target genes involved in intercellular and cell-matrix adhesions which have important roles in cell motility, cell proliferation and cell differentiation. In addition, these miRNAs were also predicted to modulate TGF- $\beta$ and MAPK signalling pathways. 


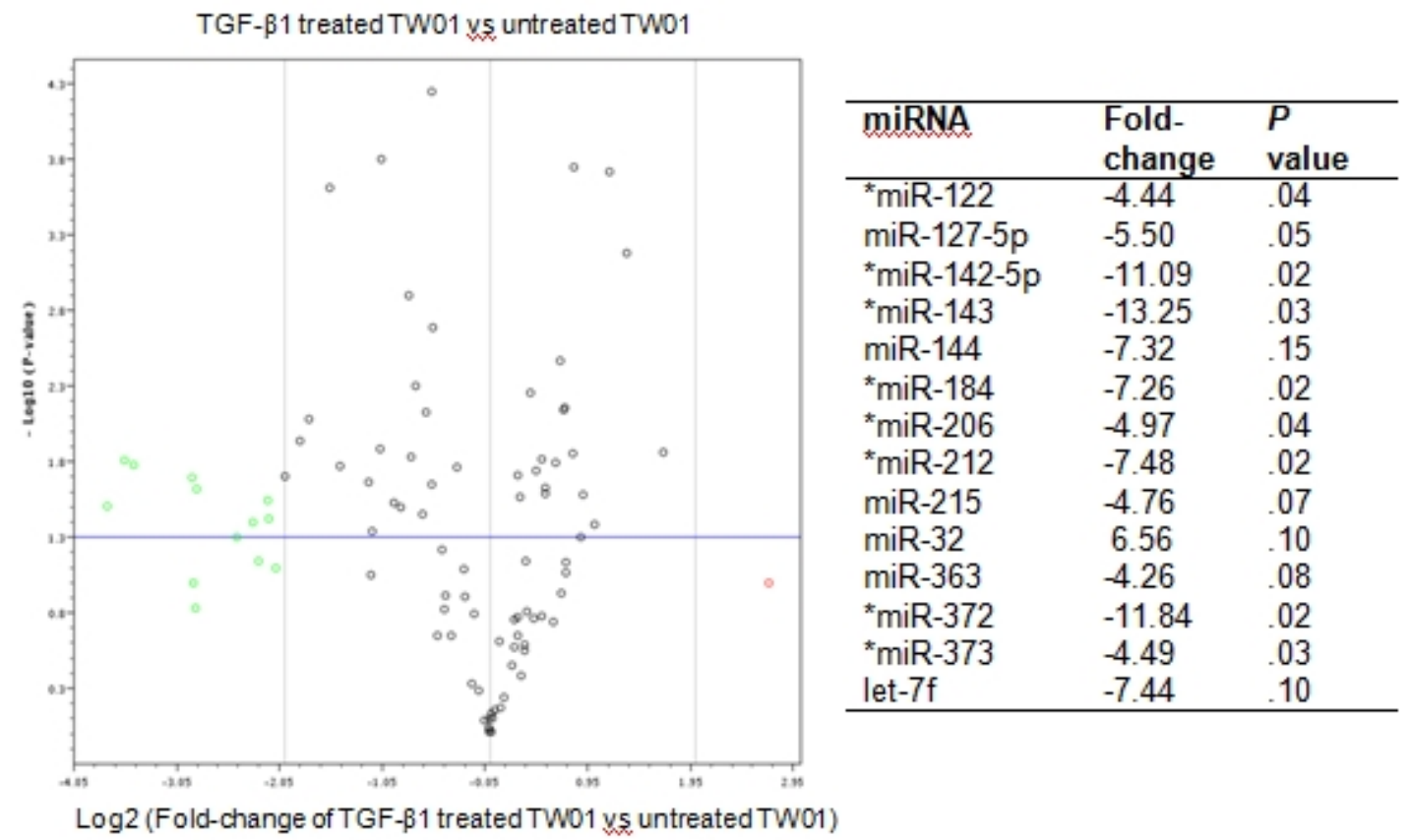

Fig. 2. Volcano plot of 88 cancer related miRNAs expressed in TW01 cells treated with TGF- $\beta 1$.

Extracted miRNAs were converted to cDNA and profiled using the RT2 miRNA PCR Array System.

The fold-change was obtained through SABiosciences web-based PCR array data analysis. Foldchange of more than four was used as a threshold limit, with green circle indicating <-4 and red circle indicating $>4$. * indicates $P$ value $<.05$ as compared to the untreated TW01 cells. All experiments were performed in triplicates.

As shown in Fig.3, expression of EBV LMP1 gene in TW01 cells down-regulated approximately $32 \%$ of the 88 miRNAs as compared to control TW01 cells (without EBV LMP1 gene). Two miRNAs were significantly down-regulated with more than four-fold, namely miR-142-5p $(-5.30)$ and miR-181c $(-37.66)$. It was interesting to observe that TGF$\beta 1$ up-regulated approximately $97 \%$ of the studied miRNAs in TW0-LMP1 cells as compared to the untreated TW0-LMP1 control (Fig.4). Four miRNAs; namely, miR-127-5p, miR-181b, miR-181c and miR-181d were significantly up-regulated with miR-181c achieving approximately 56 -fold $(P=.001)$. It was noted that EBV LMP1 down-regulated miR-181c in TW01 cells but in the presence of TGF- $\beta 1$, miR-181c was up-regulated. Members of the miR-181 family including miR-181c were induced in hepatic stem cell-like hepatocellular carcinomas. However, they were repressed in mature hepatocyte-like carcinomas and thus implicating their roles in the regulation of cell differentiation [34, 35]. Down-regulation of miR181c by LMP1 might be associated with its role in cell differentiation. It was reported that LMP1 inhibited tumour cell differentiation in the early-stage of non-keratinizing NPC via down-regulation of $\mathrm{y}$-catenin [36] and LMP1 increased the rate of keratinocyte proliferation but repressed the expression of genes involved in epithelial differentiation [37, 38]. miR-181c is known to repress NOTCH2/4 and KRAS in gastric cancer [39]. Thus, down-regulation of miR-181c might lead to the derepression of Notch that would lead to the progression of NPC and an increase of the cancer stem-like side population cells [40]. Further studies would be needed to clarify the roles of miR-181c in NPC. 


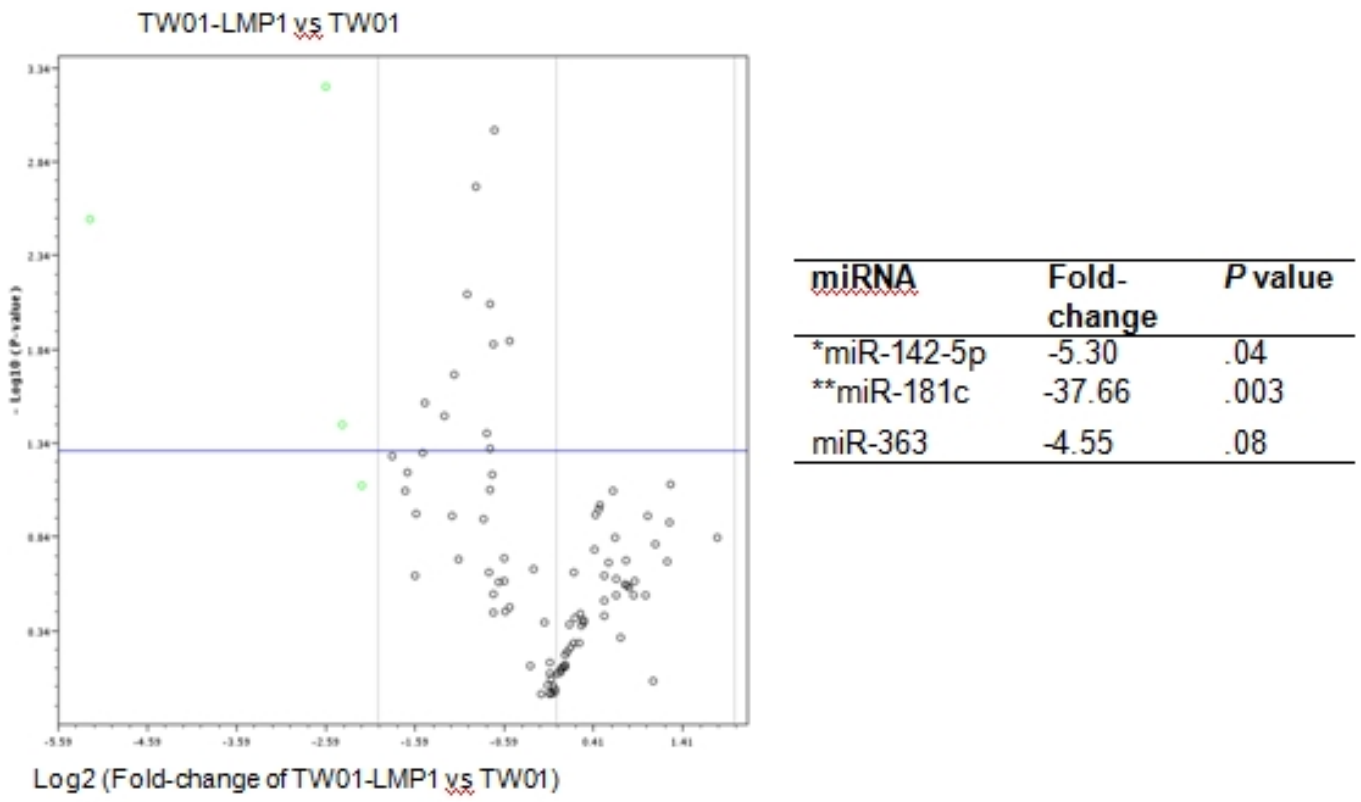

Fig. 3. Volcano plot of 88 cancer related miRNAs expressed in TW01 cells expressing LMP1 gene

Extracted miRNAs were converted to cDNA and profiled using the RT2 miRNA PCR Array System. The fold-change was obtained through SABiosciences web-based PCR array data analysis. Foldchange of more than four was used as a threshold limit, with green circle indicating $<-4$ and red circle indicating $>4$. * indicates $P$ value $<.05$ and ${ }^{* *}$ indicates $P$ value $<.01$ as compared to the untreated TW01 cells. All experiments were performed in triplicates.

Approximately $65 \%$ of the miRNAs were up-regulated by IL-6 in TW01 cells. However, the fold-change was less than four. Nevertheless, the deregulation of these miRNAs might be important as fold-change of less than two-fold could be as significant as those with more than 10 to 20 -fold differences [41]. Therefore, fold-change of more than two was used as a threshold limit for data analysis of this treatment. Three miRNAs; namely, miR-146a, miR335 and miR-98 were up-regulated significantly (Fig.5A). miR-355 targets Rb1 and thus, plays an important role in controlling proliferation by the induction of p53-dependent cell cycle arrest [42]. Down-regulation of miR-98 was observed in relapsed NPC patients and miR-98 was involved in the regulation of enhancer of Zeste homolog 2 (EZH2) [43]. Interestingly, IL-6 was reported to induce expression of EZH2 in growth factor-dependent cell lines, but during terminal differentiation induced by IL-6, the B lymphoblastoid cell line (CESS) lost EZH2 expression [44]. Induction of miR-146a inhibited the invasive capacity via reduction of EGFR and the NF-KB regulatory kinase interleukin 1 receptor-associated kinase 1 (IRAK-1) [45]. Interestingly, the presence of IL-6 induced the expression of tumour suppressors in TW01. In addition, miR-222 that is known to target tumour suppressor p2 $7^{\text {Kip } 1}$ [46], was down-regulated in the presence of IL-6. This was consistent with the growth inhibitory effect of IL-6 by preventing the degradation of p2 ${ }^{\text {Kip1 }}$ [47]. 
TW01-LMP1 treated with TGF-ß1 ys untreated TW01-LMP1

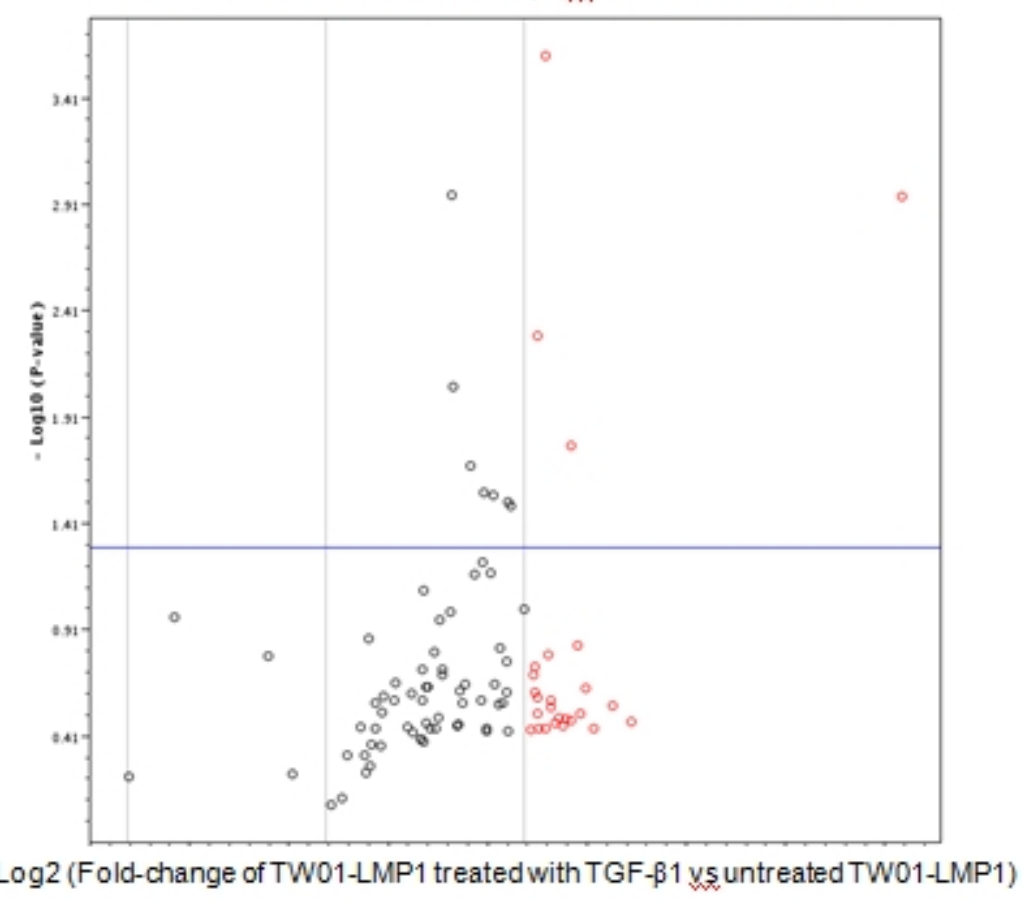

\begin{tabular}{lll}
\hline miRNA & $\begin{array}{l}\text { Fold- } \\
\text { change }\end{array}$ & $\boldsymbol{P}$ value \\
\hline miR-10a & 4.20 & .36 \\
miR-10b & 4.62 & .36 \\
${ }^{*}$ miR-127-5p & 5.52 & .017 \\
miR-132 & 4.81 & .28 \\
miR-134 & 4.38 & .25 \\
miR-144 & 4.96 & .33 \\
miR-146b-5p & 4.71 & .16 \\
miR-15b & 4.82 & .26 \\
miR-155 & 8.45 & .33 \\
${ }^{* *}$ miR-181b & 4.40 & .005 \\
${ }^{* *}$ miR-181c & 55.78 & .001 \\
${ }^{* * * m i R-181 d ~}$ & 4.65 & .0002 \\
miR-183 & 5.26 & .34 \\
\hline
\end{tabular}

\begin{tabular}{lll}
\hline miRNA & $\begin{array}{l}\text { Fold- } \\
\text { change }\end{array}$ & $\boldsymbol{P}$ value \\
\hline miR-184 & 4.37 & .30 \\
miR-196a & 5.35 & .32 \\
miR-203 & 5.55 & .32 \\
miR-206 & 4.30 & .18 \\
miR-21 & 5.10 & .31 \\
miR-215 & 6.51 & .35 \\
miR-218 & 4.29 & .24 \\
miR-23b & 5.92 & .30 \\
miR-25 & 4.43 & .35 \\
miR-32 & 4.27 & .20 \\
miR-373 & 6.13 & .23 \\
miR-7 & 5.82 & .15 \\
miR-9 & 7.40 & .28 \\
\hline
\end{tabular}

Fig. 4. Volcano plot of 88 cancer related miRNAs expressed in TW01-LMP1 cells treated with TGF- $\beta 1$

Extracted miRNAs were converted to cDNA, profiled using the RT2 miRNA PCR Array System and analysed as described in Material and Methods. Fold-change of more than four was used as a threshold limit, with green circle indicating $<-4$ and red circle indicating $>4$. * indicates $P$ value $<.05$, ** indicates $P$ value $<.01$ and ${ }^{* * *}$ indicates $P$ value $<.001$ as compared to the untreated TW01-LMP1 cells. All experiments were performed in triplicates. 
Presence of IL-6 caused up-regulation of $67 \%$ miRNAs in TW01-LMP1 as compared to control. Eight miRNAs; namely, miR-15b, miR-155, miR-16, miR-215, miR-23b, miR-25, miR-9 and miR-98 were significantly up-regulated with fold-change more than four (Fig.5B). miR-15b, miR-155 and miR-25 were found to be elevated in NPC tissues [3] and miR-155 is an activator of the NF-KB signalling pathway in many cancers [48]. In NPC, LMP1 was reported to up-regulate miR-155 that targets Jumonji domain $1 \mathrm{~A}$ (JMJD1) and is associated with poor prognosis [49]. miR-16 was reported to target the tumour suppressor BRCA-1 in NPC leading to tumour growth [50]. It was noted that treatment of IL-6 in TW01 cells that expressed EBV LMP1 resulted in the up-regulation of oncogenes that are associated with cancer progression. Although miR-98 was up-regulated by IL-6 in both TW01 and TW0LMP1 cells, it is important to note that miR-98 was also speculated to target tumour suppressor gene, FUS1 [51]. To date, the role of miR-98 in NPC development and its association with IL-6 or LMP-1 has not been reported.

A TW01 treated with IL-6 ys untreated TW01

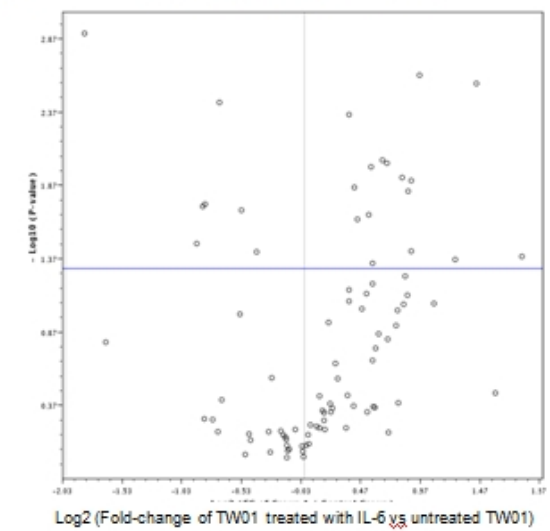

\begin{tabular}{lll}
\hline miRNA & $\begin{array}{l}\text { Fold- } \\
\text { change }\end{array}$ & $\begin{array}{l}P \\
\text { value }\end{array}$ \\
\hline${ }^{m i R-143}$ & -3.16 & .16 \\
${ }^{* \star}$ miR-146a & 2.71 & .003 \\
miR-181d & 3.03 & .35 \\
${ }^{* \star}$ miR-222 & -3.59 & .001 \\
${ }_{m i R}-32$ & 2.13 & .09 \\
${ }^{*}$ miR-335 & 3.54 & .04 \\
${ }^{*}$ miR-98 & 2.40 & .04 \\
\hline
\end{tabular}

B TW01-LMP1 treated with IL-6 ys untreated TW01-LMP1

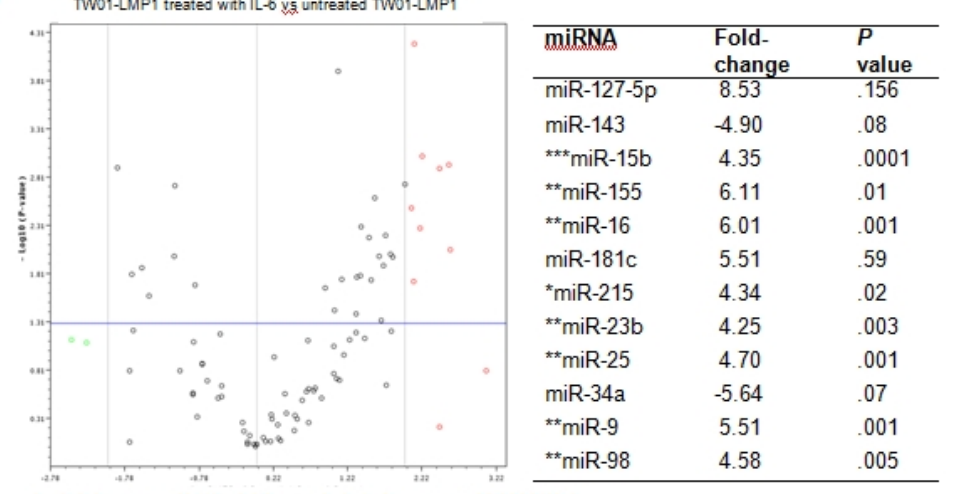

Log2 (Fold-change of TW01-LMP1 treated with IL-6 vs untreated TW01-LMP1)

Fig. 5. Volcano plot of 88 cancer related miRNAs expressed in (A) TW01 cells and (B) TW01-LMP1 cells treated with IL-6

Extracted miRNAs were converted to cDNA, profiled using the RT2 miRNA PCR Array System and analysed as described in Material and Methods. Fold-change $>2$ was used as a threshold limit in $(A)$ while fold-change $>4$ was used in (B). Green circle indicating $<-4$ and red circle indicating $>4$. * indicates $P$ value $<.05$, ** indicates $P$ value $<.01$ and ${ }^{* * *}$ indicates $P$ value $<.001$ as compared to the respective control (untreated TW01/TW01-LMP1 cells). All experiments were performed in triplicates. 


\section{CONCLUSION}

In summary, the present study showed that the EBV LMP1 gene affected the expression of miRNAs in TW01 cells in response to cytokines such as TGF- $\beta 1$ and IL-6. TGF- $\beta 1$ caused down-regulation of eight miRNAs, namely, miR-122, miR-142-5p, miR-143, miR-184, miR206, miR-212, miR-372 and miR-373. However, when LMP1 was expressed, treatment with TGF- $\beta 1$ resulted in the up-regulation of approximately $97 \%$ of the miRNAs considered in this study. These included miR-127-5p, miR-181b, miR-181c and miR-181d. Finally, treatment with IL6 induced the up-regulation of $65 \%$ miRNAs with none of these, reaching fold-change above four. In TW01-LMP1 cells, eight miRNAs (miR-15b, miR-155, miR-16, miR-215, miR23b, miR-25, miR-9 and miR-98) were up-regulated more than four-fold.

\section{CONSENT}

Not applicable

\section{ETHICAL APPROVAL}

Not applicable

\section{ACKNOWLEDGEMENTS}

We would like to extend our deepest gratitude to MOHE for their funding on this research project via the FRGS grant (FRGS/1/10/ST/IMU/02/1) and for providing financial support for the studentship through MyMaster.

\section{COMPETING INTERESTS}

Authors have declared that no competing interests exist.

\section{REFERENCES}

1. Filipowicz W, Bhattacharyya SN, Sonenberg N. Mechanisms of post-transcriptional regulation by microRNAs: are the answers in sight? Nat Rev Genet. 2008;9(2):102-14.

2. Calin GA, Sevignani C, Dumitru CD, Hyslop T, Noch E, Yendamuri S, et al. Human microRNA genes are frequently located at fragile sites and genomic regions involved in cancers. Proc Natl Acad Sci USA. 2004;101(9):2999-3004.

3. Chen HC, Chen GH, Chen YH, Liao WL, Liu CY, Chang KP, et al. MicroRNA deregulation and pathway alterations in nasopharyngeal carcinoma. $\mathrm{Br} \mathrm{J}$ Cancer. 2009;100(6):1002-11.

4. Zhang L, Deng T, Li X, Liu H, Zhou H, Ma J, et al. microRNA-141 is involved in a nasopharyngeal carcinoma-related genes network. Carcinogenesis. 2010;31(4):55966.

5. Lin CT, Kao HJ, Lin JL, Chan WY, Wu HC, Liang ST. Response of nasopharyngeal carcinoma cells to Epstein-Barr virus infection in vitro. Lab Invest. 2000;80(8):1149-60.

6. Libermann TA, Baltimore D. Activation of interleukin-6 gene expression through the NF-kappa B transcription factor. Mol Cell Biol. 1990;10(5):2327-34.

7. Massague J. TGF beta in Cancer. Cell. 2008;134(2):215-30. 
8. di Renzo L, Altiok A, Klein G, Klein E. Endogenous TGF-beta contributes to the induction of the EBV lytic cycle in two Burkitt lymphoma cell lines. Int J Cancer. 1994;57(6):914-9.

9. Xu J, Ahmad A, Jones JF, Dolcetti R, Vaccher E, Prasad U, et al. Elevated serum transforming growth factor beta1 levels in Epstein-Barr virus-associated diseases and their correlation with virus-specific immunoglobulin $\mathrm{A}(\lg \mathrm{A})$ and $\lg \mathrm{M}$. J Virol. 2000;74(5):2443-6.

10. Baumforth KR, Young LS, Flavell KJ, Constandinou C, Murray PG. The Epstein-Barr virus and its association with human cancers. Mol Pathol. 1999;52(6):307-22.

11. Keryer-Bibens C, Pioche-Durieu C, Villemant C, Souquere S, Nishi N, Hirashima M, et al. Exosomes released by EBV-infected nasopharyngeal carcinoma cells convey the viral latent membrane protein 1 and the immunomodulatory protein galectin 9 . BMC Cancer. 2006;6:283.

12. Horikawa T, Yoshizaki T, Kondo S, Furukawa M, Kaizaki Y, Pagano JS. Epstein-Barr Virus latent membrane protein 1 induces Snail and epithelial-mesenchymal transition in metastatic nasopharyngeal carcinoma. $\mathrm{Br} \mathrm{J}$ Cancer. 2011;104(7):1160-7.

13. Murono S, Inoue H, Tanabe T, Joab I, Yoshizaki T, Furukawa M, et al. Induction of cyclooxygenase-2 by Epstein-Barr virus latent membrane protein 1 is involved in vascular endothelial growth factor production in nasopharyngeal carcinoma cells. Proceedings of the National Academy of Sciences of the United States of America. 2001;98(12):6905-10.

14. Tsao SW, Tramoutanis G, Dawson CW, Lo AK, Huang DP. The significance of LMP1 expression in nasopharyngeal carcinoma. Semin Cancer Biol. 2002;12(6):473-87.

15. Petrocca $F$, Vecchione A, Croce CM. emerging Role of miR-106b-25/ miR-17-92 clusters in the control of transforming growth factor $\beta$ signaling. Cancer Res. 2008;68(20):8191-4.

16. Zavadil J, Narasimhan M, Blumenberg M, Schneider RJ. Transforming growth factor- $\beta$ and microRNA: mRNA regulatory networks in epithelial plasticity. Cells Tissues Organs. 2007; 185:157-61.

17. Kato M, Putta S, Wang M, Yuan H, Lanting L, Nair I, et al. TGF- $\beta 1$ activates Akt kinase via a microRNA-dependent amplifying circuit targeting PTEN. Nat Cell Biol. 2009;11(7):881-9.

18. Yuan B, Dong R, Shi D, Zhou Y, Zhao Y, Miao M, et al. Down-regulation of miR-23b may contribute to activation of the TGF-beta1/Smad3 signalling pathway during the termination stage of liver regeneration. FEBS Lett. 2011;585(6):927-34.

19. Kong W, Yang H, He L, Zhao JJ, Coppola D, Dalton WS, et al. MicroRNA-155 is regulated by the transforming growth factor beta/Smad pathway and contributes to epithelial cell plasticity by targeting RhoA. Mol Cell Biol. 2008;28(22):6773-84.

20. Kurowska-Stolarska M, Alivernini S, Ballantine LE, Asquith DL, Millar NL, Gilchrist DS, et al. MicroRNA-155 as a proinflammatory regulator in clinical and experimental arthritis. Proc Natl Acad Sci U S A. 2011;108(27):11193-8.

21. Graziana G, Annalisa R, Daniela R, Kroening S, Bonatti S, Mallardo M. Epstein-Barr virus latent membrane protein 1 trans-activates miR-155 transcription through the NFKB pathway. Nucleic Acids Res. 2008;36(20):6608-19.

22. Chew MM, Gan SY, Khoo AS, Tan EL. Interleukins, laminin and Epstein - Barr virus latent membrane protein 1 (EBV LMP1) promote metastatic phenotype in nasopharyngeal carcinoma. BMC Cancer. 2010;10:574.

23. Coulouarn C, Factor VM, Andersen JB, Durkin ME, Thorgeirsson SS. Loss of miR-122 expression in liver cancer correlates with suppression of the hepatic phenotype and gain of metastatic properties. Oncogene. 2009;28:3526-36. 
24. Zhang X, Yan Z, Zhang J, Gong L, Li W, Cui J, et al. Combination of hsa-miR-375 and hsa-miR-142-5p as a predictor for recurrence risk in gastric cancer patients following surgical resection. Ann Oncol. 2011;22(10):2257-66.

25. Song $T$, Zhang $X$, Wang $C$, Wu Y, Dong J, Gao J, et al. Expression of miR-143 reduces growth and migration of human bladder carcinoma cells by targeting cyclooxygenase-2. Asian Pac J Cancer Prev. 2011;12:929-33.

26. Zhang T, Liu M, Wang C, Lin C, Sun Y, Jin D. Down-regulation of MiR-206 promotes proliferation and invasion of laryngeal cancer by regulating VEGF expression. Anticancer Res. 2011;31:3859-63.

27. Wang X, Tang S, Le SY, Lu R, Rader JS, Meyers C, et al. Aberrant expression of oncogenic and tumor-suppressive microRNAs in cervical cancer is required for cancer cell growth. PloS ONE. 2008;3:e2557.

28. Akao Y, Nakagawa Y, Kitade Y, Kinoshita T, Naoe T. Downregulation of microRNAs143 and -145 in B-cell malignancies. Cancer Sci. 2007;98:1914-20.

29. Clapé C, Fritz V, Henriquet C, Apparailly F, Fernandez PL, Iborra F, et al. miR-143 interferes with ERK5 signaling, and abrogates prostate cancer progression in mice. PLoS ONE. 2009;4(10):e7542.

30. Tian RQ, Wang XH, Hou LJ, Jia WH, Yang Q, Li YX, et al. MicroRNA-372 is downregulated and targets cyclin-dependent kinase 2 (CKD2) and Cyclin A1 in human cervical cancer, which may contribute to tumorigenesis. J Biol Chem. 2011;286(29):25556-63.

31. Voorhoeve PM, le Sage C, Schrier M, Gillis AJ, Stoop H, Nagel R, et al: A genetic screen implicates miRNA-372 and miRNA-373 as oncogenes in testicular germ cell tumors. Cell. 2006;124:1169-81.

32. Cho WJ, Shin JM, Kim JS, Lee MR, Hong KS, Lee JH, et al. miR-372 regulates cell cycle and apoptosis of ags human gastric cancer cell line through direct regulation of LATS2. Mol Cells. 2009;28:521-7.

33. Papadopoulos GL, Alexiou P, Maragkakis M, Reczko M, Hatzigeorgiou AG. DIANAmirPath: Integrating human and mouse microRNAs in pathways. Bioinformatics. 2009;25:1991-1993.

34. Ji J, Yamashita T, Budhu A, Forgues M, Jia HL, Li C, et al. Identification of microRNA181 by genome-wide screening as a critical player in EpCAM-positive hepatic cancer stem cells. Hepatology. 2009;50:472-80.

35. Naguibneva I, Ameyar-Zazoua M, Polesskaya A, Ait-Si-Ali S, Groisman R, Souidi M, et al. The microRNA miR-181 targets the homeobox protein Hox-A11 during mammalian myoblast differentiation. Nat Cell Biol. 2006;8(3):278-84.

36. Lin S, Zong Y, Lin H, Zhong B, Li Z, Liang Y. Effects of eb virus encoded LMP1 on differentiation of nasopharyngeal carcinoma cells. Chinese Journal of Cancer Research. 2003;15(4):257-61.

37. Morris MA, Dawson CW, Wei W, O'Neil JD, Stewart SE, Jia J, et al. Epstein-Barr virus-encoded LMP1 induces a hyperproliferative and inflammatory gene expression programme in cultured keratinocytes. J Gen Virol. 2008;89:2806-20.

38. Zheng X, Yuan F, Hu L, Chen F, Klein G, Christensson B. Effect of beta-lymphocyteand NPC-derived EBV-LMP1 gene expression on in vitro growth and differentiation of human epithelial cells. Int J Cancer. 1994;57(5):747-53.

39. Hashimoto Y, Akiyama Y, Otsubo T, Shimada S, Yuasa Y. Involvement of epigenetically silenced microRNA-181c in gastric carcinogenesis. Carcinogenesis. 2010;31(5):777-84.

40. Yu S, Zhang R, Liu F, Wang H, Wu J, Wang Y. Notch inhibition suppresses nasopharyngeal carcinoma by depleting cancer stem-like side population cells. Oncol Rep. 2012;28(2):561-6. 
41. Calin GA, Croce CM. MicroRNA signatures in human cancers. Nat Rev Cancer. 2006;6:857-66.

42. Scarola M, Schoeftner S, Schneider C, Benetti R. miR-335 directly targets Rb1 ( $\mathrm{pRb} / \mathrm{p} 105)$ in a proximal connection to p53-dependent stress response. Cancer Res. 2010;70(17):6925-33.

43. Alajez NM, Shi W, Hui ABY, Bruce J, Lenarduzzi M, Ito E, Yue S, O'Sullivan B and Liu FF (2010) Enhancer of Zeste homolog 2 (EZH2) is overexpressed in recurrent nasopharyngeal carcinoma and is regulated by miR-26a, miR-101, and miR-98. Cell Death and Disease

44. Croonquist PA and Ness B. The polycomb group protein enhancer of zeste homolog 2 $(\mathrm{EZH} 2)$ is an oncogene that influences myeloma cell growth and the mutant ras phenoty. Oncogene. 2005;24:6269-6280.

45. Li Y, VandenBoom II TG, Wang Z, Kong D, Ali S, Philip PA, et al. miR-146a Suppresses Invasion of Pancreatic Cancer Cells. Cancer Res. 2010;70(4):1486-95.

46. Galardi S, Mercatelli N, Giorda E, Massalini S, Frajese GV, Ciafre SA, et al. miR-221 and miR-222 expression affects the proliferation potential of human prostate carcinoma cell lines by targeting p27 ${ }^{\text {Kip1 }}$. J Biol Chem. 2007;282(32):23716-24.

47. Klausen $P$, Pedersen L, Jurlander J, Baumann $H$. Oncostatin $M$ and interleukin 6 inhibit cell cycle progression by prevention of p2 $7^{\text {kip } 1}$ degradation in HepG2 cells. Oncogene. 2000;19(32):3675-83.

48. Rai D, Karanti S, Jung I, Dahia PL, Aguiar RC. Coordinated expression of microRNA155 and predicted target genes in diffuse large B-cell lymphoma. Cancer Genet Cytogenets 181: 8-15.

49. Du ZM, Hu LF, Wang HY, Yan LX, Zeng YX, Shao JY, et al. Upregulation of miR-155 in nasopharyngeal carcinoma is partly driven by LMP1 and LMP2A and downregulates a negative prognostic marker JMJD1A. PLoS ONE. 2011;6(4):e19137.

50. Zhu JY, Pfuhl T, Motsch N, Barth S, Nicholls J, Grasser F, et al. Identification of novel Epstein-Barr virus microRNA genes from nasopharyngeal carcinoma. J Virol. 2009;83(7):3333-41.

51. Du L, Schageman JJ, Subauste MC, Saber B, Hammond SM, Prudkin L, et al. miR-93, miR-98 and miR-197 regulate expression of tumor suppressor gene FUS1. Mol Cancer Res. 2009;7(8):1234-43.

(C) 2013 Lee et al.; This is an Open Access article distributed under the terms of the Creative Commons Attribution License (http://creativecommons.org/licenses/by/3.0), which permits unrestricted use, distribution, and reproduction in any medium, provided the original work is properly cited.

Peer-review history:

The peer review history for this paper can be accessed here: http://www.sciencedomain.org/review-history.php?iid=194\&id=12\&aid=987 